\title{
Safety and tolerability of flexible dosages of prolonged-release OROS methylphenidate in adults with attention-deficit/hyperactivity disorder
}

\author{
This article was published in the following Dove Press journal: \\ Neuropsychiatric Disease and Treatment \\ 24 August 2009 \\ Number of times this article has been viewed
}

\begin{abstract}
Jan K Buitelaar'
J Antoni Ramos-Quiroga ${ }^{2}$

Miguel Casas ${ }^{2}$

J J Sandra Kooij ${ }^{3}$

Asko Niemelä4

Eric Konofal ${ }^{5}$

Joachim Dejonckheere ${ }^{6}$

Bradford $\mathrm{H} \mathrm{Challis}^{7}$

Rossella Medori ${ }^{8}$

'Department of Psychiatry, University Medical Center, St. Radboud and

Karakter Child and Adolescent Psychiatry University Center,

Nijmegen, The Netherlands;

${ }^{2}$ Department of Psychiatry, Hospital

Universitari Vall d'Hebron and

Department of Psychiatry and Legal

Medicine, Universitat Autònoma

de Barcelona, Barcelona, Spain;

${ }^{3}$ PsyQ, Psycho-Medical Programs,

Program Adult ADHD, Den Haag,

The Netherlands; ${ }^{4}$ Oulu University

Hospital, Department of Psychiatry,

Oulu, Finland; ${ }^{5}$ Groupe Hospitalier

Pitie-Salpetriere, Paris, France;

${ }^{6} \mathrm{SGS}$ Life Sciences, Mechelen, Belgium;

${ }^{7}$ Johnson \& Johnson Pharmaceutical

Research and Development, Titusville, NJ, USA; ${ }^{8}$ Janssen-Cilag EMEA, Neuss, Germany
\end{abstract}

Correspondence: Jan K Buitelaar Donders Institute for Brain, Behavior and Cognition, Radboud University Nijmegen Medical Center, Department of Psychiatry (966), PO Box 9I0I, 6500 HB Nijmegen, The Netherlands

$\mathrm{Tel}+3$ I 24346 I 3490

Fax +3I 24354056 I

Email j.buitelaar@psy.umcn.nl
Abstract: The osmotic release oral system (OROS) methylphenidate formulation is a prolonged-release medication for the treatment of attention-deficit/hyperactivity disorder (ADHD) in children, adolescents, and adults. We conducted a seven-week open-label extension of a double-blind study to assess the safety and tolerability of OROS methylphenidate in a flexible dose regimen (18-90 mg daily) for the treatment of adults diagnosed with ADHD ( $\mathrm{N}=370$ ). Medication was adjusted to optimize efficacy and tolerability for each patient. Adverse events, vital signs, and laboratory parameters were assessed. Most patients (337; 91\%) completed the seven-week treatment and the final dispensed dose was $18 \mathrm{mg}(8 \%), 36 \mathrm{mg}(29 \%), 54 \mathrm{mg}$ (34\%), $72 \mathrm{mg}$ (20\%), or $90 \mathrm{mg}$ (9\%). Adverse events were reported in 253 (68\%) patients and most were mild or moderate in severity; most frequently reported included headache $(17 \%)$, decreased appetite (13\%), and insomnia (11\%). Adverse events were rarely serious $(<1 \%$; 2/370). Small mean increases in systolic and diastolic blood pressure (both $2.4 \mathrm{mmHg}$ ) and pulse $(3.2 \mathrm{bpm})$ were observed. Body weight decreased slightly $(-1.5 \mathrm{~kg})$. The results provide additional support for the safety and tolerability of prolonged-release OROS methylphenidate in a flexible dose regimen (18-90 mg/day) for the treatment of adults with ADHD.

Keywords: attention deficit hyperactivity disorder, ADHD, adult, methylphenidate, safety

\section{Introduction}

There is increasing recognition of the need for treatment of attention-deficit/hyperactivity disorder (ADHD) in adults, with mounting evidence that symptoms persist beyond childhood. ${ }^{1}$ Adults show similar responsiveness to methylphenidate treatment for ADHD as seen in children. ${ }^{2-12}$ Recent literature reviews of the safety of methylphenidate in the treatment of ADHD in adults and other conditions concluded that the medication is effective and well tolerated. ${ }^{13,14} \mathrm{~W}$ ith growing support for methylphenidate treatment of ADHD in adults, the safety and tolerability of methylphenidate formulations and regimens in treatment of ADHD in adults merit further investigation. ${ }^{15-17}$

The osmotic release oral system (OROS) methylphenidate formulation is designed to deliver methylphenidate in a controlled manner for approximately 12 hours, thereby allowing extended coverage of symptoms during the day. This long-acting formulation, designed for once-a-day administration, was shown to be an effective and safe treatment of ADHD in children and adolescents, ${ }^{18-20}$ and more recently in adults. ${ }^{21-24}$ This prolonged-release medication (Concerta ${ }^{\circledR}$; McNeil Pediatrics Division of Ortho-McNeil-Janssen Pharmaceuticals, Inc, Titusville, NJ, USA) is approved for

submit your manuscript | www.dovepress.con 
the treatment of ADHD in children and adolescents in various countries, and for the treatment of ADHD in adults in the United States and Canada.

Recently, Medori and colleagues ${ }^{23}$ reported findings from a double-blind, placebo-controlled trial in which three fixed doses of OROS methylphenidate were administered once daily over five weeks for the treatment of ADHD in 401 adults. The three dosages of medication $(18,36$, $72 \mathrm{mg}$ ) were each an effective treatment of ADHD in adults, with a safety and tolerability profile consistent with methylphenidate use in children and adolescents. The trial included a subsequent open-label treatment phase to evaluate the safety of the medication under treatment conditions more consistent with actual clinical practice. In the open-label phase, patients received a flexible dose regimen of the medication (18-90 mg daily) to optimize efficacy and tolerability for each patient based on the investigators' judgment of clinical response. Flexible dosing more closely parallels clinical practice than fixed dosing and therefore may provide additional clinically relevant findings.

We report the results of the seven-week open-label extension of the Medori and colleagues trial. ${ }^{23}$ Patients who completed the double-blind phase or discontinued study medication due to poor tolerability received a flexible dose regimen of the medication (18-90 mg daily) so as to optimize efficacy and tolerability for each patient based on the investigators' judgment of clinical response. The primary purpose of the open-label phase was to evaluate the safety and tolerability of flexible dosages of OROS methylphenidate through assessments of adverse events, vital signs, clinical laboratory tests, and physical examination.

\section{Methods}

\section{Background}

Medori and colleagues reported a double-blind phase of a trial in which adults with ADHD (18-65 years) were randomly assigned to receive OROS methylphenidate $(18,36$, or $72 \mathrm{mg} /$ day) or placebo for five weeks. Study procedures included administration of efficacy measures, monitoring of adverse events, clinical laboratory tests (hematology, biochemistry), vital signs (supine and standing blood pressure, pulse), and physical examination at baseline and at the end of weeks 1, 3, and 5, or at early withdrawal. Patients who completed the double-blind phase or discontinued the double blind phase of the study due to poor tolerability were eligible to participate in a seven-week open-label extension during which they received a flexible dose regimen of prolonged release (PR) OROS methylphenidate (18-90 mg/day) with adjustment to optimize efficacy and tolerability for each patient based on the investigators' judgment of clinical response.

Of the original 401 patients enrolled in the double-blind trial, $370(92 \%)$ continued to the open-label phase of the study. Of these 370 patients, 363 (98.1\%) had previously completed the double-blind study and seven $(1.9 \%)$ had not due to lack of efficacy (five patients) or adverse events (two patients). The discontinuations due to adverse events included one patient in the $36 \mathrm{mg}$ /day treatment group described as having ongoing delusion of reference that resolved during the treatment interruption, and a second patient in the $72 \mathrm{mg} /$ day group who reported anxiety, psychomotor agitation, disturbance in attention, and irritability.

The trial was conducted at 51 investigator sites in 13 European countries (listed in Acknowledgments) from April 2005 to June 2006. Ethics Committee approval was obtained and patients gave informed consent to participate.

\section{Patients}

The trial included adult men and women with a diagnosis of ADHD according to the criteria of the Diagnostic and Statistical Manual of Mental Disorders, Fourth Edition (DSM-IV), ${ }^{25}$ and confirmed by the Conners' Adult ADHD Diagnostic Interview for DSM-IV (CAADID). ${ }^{26}$ Other requirements for inclusion were: age 18-65 years; chronic course of ADHD symptomatology from childhood to adulthood with some symptoms present before 7 years of age, as determined by investigators following the CAADID interview; and total score of $\geq 24$ at screening on Conners' Adult ADHD Rating Scale (CAARS; Investigatorrated). ${ }^{26}$ The Structured Clinical Interview for DSM-IV Axis I Disorders (SCID-I) was used to evaluate the presence of other comorbidities. ${ }^{27}$ The diagnosis of ADHD was not made if symptoms were better accounted for by another psychiatric disorder (eg, mood, anxiety, psychotic, personality disorder). Patients were excluded if: the investigator judged they (or their child) had a history of poor response or intolerance to methylphenidate; diagnosed with any current clinically unstable psychiatric condition (eg, acute mood disorder, bipolar disorder, acute obsessive-compulsive disorder), as determined by the investigator; or diagnosed with substance use disorder (abuse/dependence) according to DSM-IV criteria within the last six months. Other exclusion criteria included family history of schizophrenia or affective psychosis; serious illnesses (eg, hepatic or renal insufficiency, significant cardiac, gastrointestinal, psychiatric, or metabolic disturbances); hyperthyroidism, myocardial infarction, or 
stroke within six months of screening; and history of seizures, glaucoma, or uncontrolled hypertension.

Patients were eligible to continue in the seven-week open-label extension if they still met the initial inclusion and exclusion criteria (except for criteria concerning prior treatment with methylphenidate and CAARS score $\geq 24$ ) and they completed the double-blind phase or discontinued treatment after a minimum of seven treatment days. Patients who had received a stable dose of an antidepressant (except MAO inhibitors) for at least three months prior to screening could continue this treatment at the same dose during the open-label phase. The continued use of antidepressants (eg, citalopram, escitalopram) by only a small number of patients $(3.5 \%)$ was not expected to influence the assessment of OROS methylphenidate treatment. Patients treated at German or Spanish centers who discontinued the double-blind phase due to poor tolerability were not permitted to enter the open-label phase due to Ethics Committee requirements.

\section{Procedure}

Patients who entered the open-label extension received flexible dosages of OROS methylphenidate $(18,36,54$, 72 or $90 \mathrm{mg} /$ day) for seven weeks. Patients began with $36 \mathrm{mg} /$ day and were titrated to the most appropriate OROS methylphenidate dose to preserve the blinding of the treatment received in the double-blind phase. The $36 \mathrm{mg}$ /day dosage was considered an appropriate starting dose to maintain some efficacy for patients who were receiving $72 \mathrm{mg} /$ day OROS methylphenidate during the double-blind phase, while avoiding tolerability issues for those patients who received $18 \mathrm{mg} /$ day or placebo during the double-blind phase. Patients at German centers began with $18 \mathrm{mg} /$ day due to Ethics Committee requirements. Titration of dosing was based on clinical observations of response and tolerability. The dosage could be increased by $18 \mathrm{mg}$ increments to improve efficacy, to a maximum of $90 \mathrm{mg} /$ day, or decreased by $18 \mathrm{mg}$ increments to improve tolerability. Investigators were encouraged to wait at least seven days to change the dosage.

The final visit of the double-blind phase was considered the baseline visit for the open-label phase, and included administration of efficacy measures, clinical laboratory tests (hematology, biochemistry), vital signs, physical examination, and confirmation that the patient met the required inclusion and exclusion criteria. Study visits during the open-label phase occurred at the end of weeks 1, 3, and 7 (or early termination); procedures included vital signs, concomitant medication review, adverse event monitoring, dispensing of study medication, and study drug accountability and dosing compliance, and the CAARS efficacy measure. The final visit also included clinical laboratory tests (hematology, biochemistry) and physical examination. Designated time intervals after first intake of medication was defined as week 1 (1-13 days), week 3 (14-31 days), or week 7 ( $\geq 32$ days) during the open label phase. A post-study visit occurred one week after the last dose of study medication.

\section{Assessments}

The safety and tolerability of OROS methylphenidate treatment were addressed via assessments of adverse events (using the Medical Dictionary for Regulatory Activities), ${ }^{a}$ clinical laboratory tests, vital signs, and physical examination. A treatment-emergent adverse event was defined as any sign, symptom, syndrome, or new illness that appeared or worsened during the open-label phase, and included laboratory findings or results of other diagnostic procedures considered medically important. Adverse events were recorded throughout the open-label phase, along with action taken (none, dose reduced, drug stopped temporarily, drug stopped permanently). Based on standard definitions, the investigator judged the severity of an adverse event (mild, moderate, or serious) and relationship to the study drug (not related, doubtful, possible, probable, very likely). The evaluation of the safety data included all subjects who took at least one dose of study medication during the open-label phase. The incidence of adverse events was summarized overall and by daily dose over weeks 1, 3, and 7. Descriptive statistics were computed for each laboratory analyte, vital sign, and weight measurements.

An efficacy analysis evaluated the change in CAARS total score from end of double-blind treatment (baseline) at each visit (last observation carried forward) in patients who received at least one dose of medication and had at least one post-baseline efficacy measurement during the open-label phase. Within-group statistical testing for change from double-blind end point was performed using a two-sided paired $t$-test. All statistical analyses were performed using SAS (Version 8.02; SAS Institute, Cary, NC, USA).

\section{Results Patient disposition}

The flow of patients from the double-blind phase through the open-label phase of the trial is presented in Figure 1.

${ }^{a}$ MedDRA ${ }^{\circledR}$ : international medical terminology developed under the auspices of the International Conference on Harmonization of Technical Requirements for Registration of Pharmaceuticals for Human Use (ICH). 


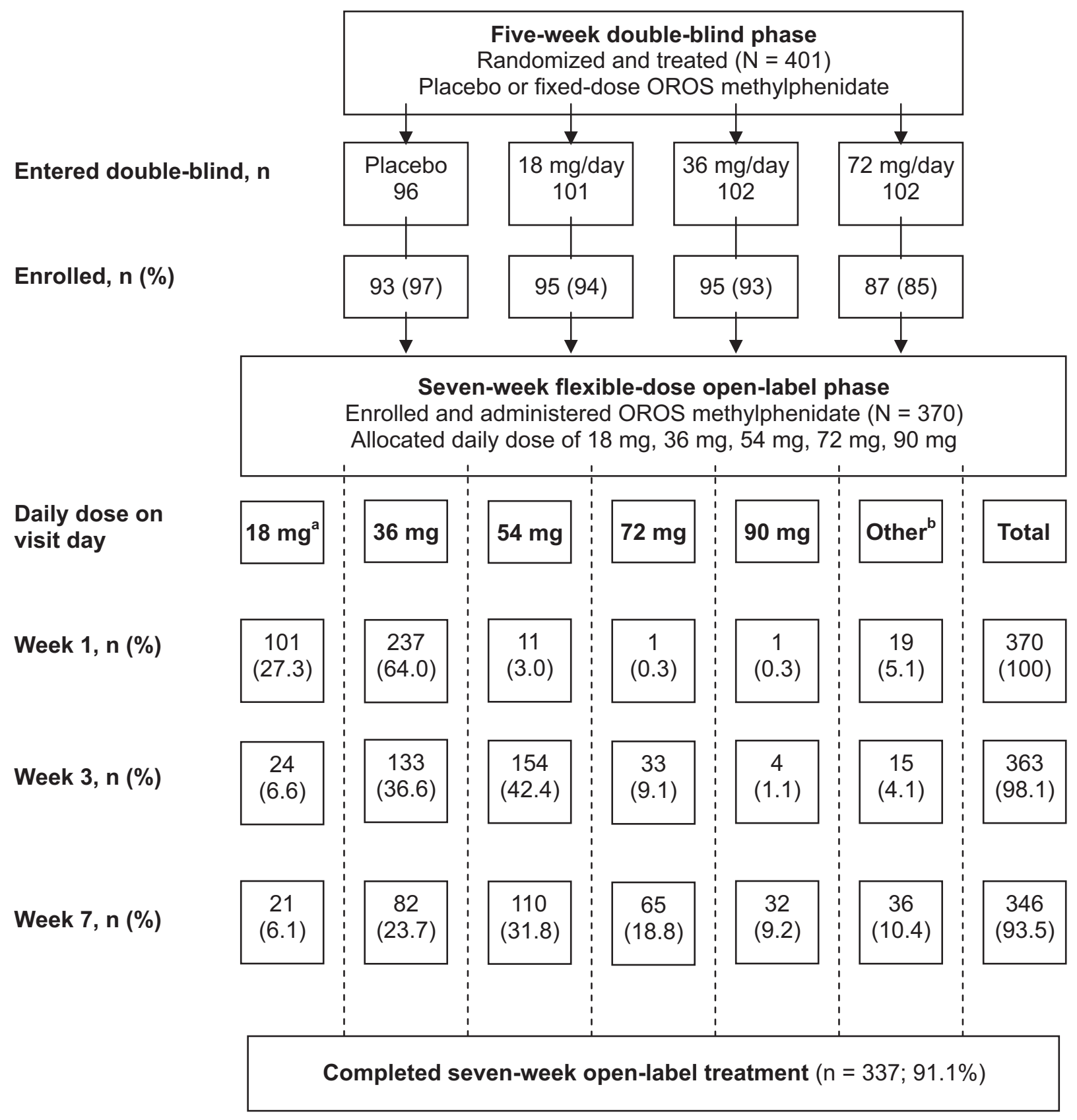

Figure I Flow of patients from the double-blind phase through the open-label phase of the trial.

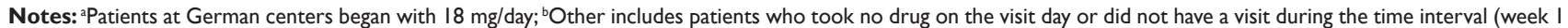
[I-13 days], week 3 [ $|4-3|$ days], week 7 [ $\geq 32$ days])

Abbreviation: OROS, osmotic release oral system.

A total of 370 patients enrolled in the open-label phase and were administered study drug. Of these patients, $337(91.1 \%)$ completed the seven-week treatment period. Eighteen $(4.9 \%)$ patients permanently discontinued treatment due to one or more adverse events and 15 (4\%) patients discontinued for other reasons (lost to follow-up [5], noncompliance [4], lack of efficacy [1], and other [5]).

Patients in the open-label phase did not differ in demographic and clinical characteristics from those randomized in the double-blind phase, which have been described elsewhere. ${ }^{23}$ For the 370 patients in the open-label phase, median age was 35 years $(\mathrm{M}=34.3, \mathrm{SD}=10.29)$, median weight was $77 \mathrm{~kg}(\mathrm{M}=78.0, \mathrm{SD}=17.13), 54 \%$ were male, and $98 \%$ were Caucasian. Median age at diagnosis of ADHD was 32 years (range $<1-63$ ), with the majority (74\%) having documented ADHD combined subtype as a child (adult diagnosis). Currently active and stable psychiatric comorbidities in the study population included mood and 
anxiety disorders in $12 \%$ of patients and personality disorders in $1 \%$ of patients.

\section{Dosage and exposure}

Mean duration of exposure was 47.6 days (range 2-90), with a mean average daily dose (excluding no dose days) of $47.5 \mathrm{mg}$, mean minimum dose of $29.4 \mathrm{mg}$, and mean maximum daily dose of $57.6 \mathrm{mg}$ (Table 1). The mean daily dose at weeks 1, 3, and 7 was $36.4 \mathrm{mg}, 49.2 \mathrm{mg}$, and $52.4 \mathrm{mg}$, respectively. The most frequently used daily dose was $36 \mathrm{mg}$ at week 1 (64\%), $54 \mathrm{mg}$ at week 3 (42\%), and $54 \mathrm{mg}$ at week 7 (32\%). The $54 \mathrm{mg}$ daily dose was most frequently administered as a last dose (34\%) and maximum dose (36\%). The other daily dosages, $18 \mathrm{mg}, 36 \mathrm{mg}, 72 \mathrm{mg}$ and $90 \mathrm{mg}$, were administered as a last dose to $8 \%, 29 \%, 20 \%$, and $9 \%$ of the patients, respectively.

\section{Adverse events}

Adverse events are summarized in Table 2 for the 370 patients. Overall, 253 (68\%) patients experienced at least one treatment-emergent adverse event. The most frequently reported adverse events were headache, decreased appetite, and insomnia, and the highest incidence was for the category nervous system disorders (35\%), psychiatric disorders (23\%), and gastrointestinal disorders (21\%). The most frequently

Table I Study medication administered during the open-label phase

\begin{tabular}{|c|c|c|c|}
\hline \multirow[t]{2}{*}{ Treatment summary ${ }^{a}$} & \multicolumn{3}{|c|}{ Descriptive statistic $(N=370)$} \\
\hline & Mean (SD) & Median & Range \\
\hline Treatment duration (days) & $47.6(9.13)$ & 49.0 & $2-90$ \\
\hline Average daily dose $(\mathrm{mg})^{\mathrm{b}}$ & $47.5(13.93)$ & 46.4 & $18-82$ \\
\hline Average daily dose $(\mathrm{mg})^{c}$ & $46.5(14.18)$ & 46.3 & $15-82$ \\
\hline Last dose (mg) & $52.6(19.29)$ & 54.0 & $18-90$ \\
\hline Maximum dose (mg) & $57.6(18.11)$ & 54.0 & $18-108$ \\
\hline Minimum dose $(\mathrm{mg})^{d}$ & $29.4(8.88)$ & 36.0 & $18-54$ \\
\hline
\end{tabular}

\begin{tabular}{lll}
\multicolumn{3}{l}{ Distribution of last dose and maximum dose, $\mathbf{n}(\%)$} \\
\hline Daily dose & Last dose & Maximum dose \\
\hline $18 \mathrm{mg}$ & $29(7.9)$ & $5(1.4)$ \\
$36 \mathrm{mg}$ & $108(29.3)$ & $96(26.0)$ \\
$54 \mathrm{mg}$ & $127(34.4)$ & $133(36.0)$ \\
$72 \mathrm{mg}$ & $73(19.8)$ & $93(25.2)$ \\
$90 \mathrm{mg}$ & $32(8.7)$ & $40(10.8)$ \\
$108 \mathrm{mg}$ & - & $2(0.5)^{\mathrm{e}}$ \\
\hline
\end{tabular}

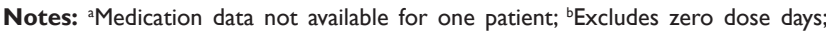
Includes zero dose days; ${ }^{\mathrm{C} E x c l u d e s}$ zero dose days; minimum dose was generally the starting dose; 'Two patients assigned to a $54 \mathrm{mg}$ daily dose took a double dose for one day and two days, respectively. occurring adverse events considered by the investigator as at least possibly related to study medication by the investigator were decreased appetite (12\%), headache (9\%), and insomnia (9\%). The majority of the adverse events were mild or moderate in severity. Two patients experienced a serious adverse event during open-label treatment. No deaths occurred in this trial.

The incidence of adverse events by daily dose over weeks 1,3 , and 7 is provided in Table 3 . The incidence (\%) of adverse events decreased for all five dosages over the seven-week treatment period. The most frequently occurring adverse events recorded at the final treatment visit (week 7) according to the patient's daily dose at this visit are presented in Table 4.

\section{Serious adverse events}

Two patients reported a serious adverse event during open-label treatment. A 40-year-old man started at a daily dose of $18 \mathrm{mg}$ that was increased to $36 \mathrm{mg}$ after one week, and 22 days later, he was admitted to the hospital due to acute psychological stress. Treatment was stopped 19 days after admission, the patient was discharged two days later, and acute psychological stress resolved five days later. The investigator assessed the event as moderate in severity and not related to study medication. A second man (age 46) reported a foreign body in the urethra, and after it was removed, the patient was considered recovered and was discharged from hospital. The investigator did not consider the adverse event related to study drug.

Two patients reported serious adverse events during the post-study period. Five days after her last dose of medication (54 mg daily), a 27-year-old woman experienced an increase in anxiety and was hospitalized in a psychiatric unit. Seven days later, the patient recovered from the event and was discharged from hospital. The investigator judged the event as severe and not related to trial medication. A 27-year-old man experienced temporal arteritis and severe headache six days after his last study medication ( $90 \mathrm{mg}$ daily) and was hospitalized for less than 12 hours. The events lasted approximately two hours and were considered serious (ie, requiring hospitalization) and considered doubtfully drug related by the investigator.

\section{Discontinuations due to adverse events}

Seventeen $(5 \%)$ patients permanently discontinued trial medication due to one or more adverse events. These adverse events included upper abdominal pain, decreased weight, decreased appetite, depressed mood and depression 
Table 2 Adverse events during the open-label phase

\begin{tabular}{ll}
\hline Category & $\begin{array}{l}\text { Treated patients } \mathbf{N}=\mathbf{3 7 0}) \\
\mathbf{n}(\%)\end{array}$ \\
\hline Any serious adverse event & $2(<\mathrm{I})$ \\
Discontinued due to adverse event & $17(5)$ \\
Any adverse event & $253(68)$ \\
Possibly related to trial medication ${ }^{\mathrm{a}}$ & $195(53)$ \\
Adverse event $>2 \%$ total $^{\mathrm{b}}$ & \\
Headache & $62(16.8)$ \\
Decreased appetite & $47(12.7)$ \\
Insomnia & $41(11.1)$ \\
Nausea & $26(7.0)$ \\
Nasopharyngitis & $21(5.7)$ \\
Restlessness & $19(5.1)$ \\
Initial insomnia & $17(4.6)$ \\
Dry mouth & $15(4.1)$ \\
Fatigue & $15(4.1)$ \\
Dizziness & $14(3.8)$ \\
Anxiety & $13(3.5)$ \\
Palpitations & $12(3.2)$ \\
Depressed mood & $11(3.0)$ \\
Tachycardia & $10(2.7)$ \\
Nervousness & $10(2.7)$ \\
Influenza & $9(2.4)$ \\
Hyperhidrosis & $9(2.4)$ \\
Disturbance in attention & $8(2.2)$ \\
\hline
\end{tabular}

Notes: ancludes relationship of 'possibly', 'probably', and 'very likely'; 'bSummarized by preferred term according to Medical Dictionary for Regulatory Activities (MedDRA).

each reported by two patients. The onset of these adverse events occurred at different daily dosages, with three events at $18 \mathrm{mg}, 13$ at $36 \mathrm{mg}$, seven at $54 \mathrm{mg}$, and two at $72 \mathrm{mg}$. Patients recovered from these adverse events, except for a report of depressed mood in one patient and decreased weight in another patient. The daily dosage was $36 \mathrm{mg}$ at the onset of these two adverse events. The investigators considered decreased weight as moderate and probably related to the trial medication, and depressed mood as mild and doubtfully related to the trial medication.

\section{Laboratory values}

Abnormal laboratory values were infrequently reported as adverse events. There were no discontinuations due to laboratory-related adverse events and none of these adverse events were reported as serious or severe, except for one patient with an abnormally increased creatine phosphokinase level. The event was considered not drug-related and resolved three weeks after completion of the study. There were no other clinically notable mean changes in laboratory values over time.

\section{Cardiovascular-related effects}

Small mean increases in systolic and diastolic blood pressure and pulse were observed during the open-label phase. The mean (SD) increase in blood pressure from the end of double-blind treatment to the end of open-label was 2.4 (14.9) $\mathrm{mmHg}$ for systolic and $2.4 \mathrm{mmHg}(9.5)$ diastolic (measured while patient was standing). The increase in standing pulse was 3.2 (14.4) beats per minute (bpm). These modest changes were not considered clinically significant.

Changes in blood pressure and pulse during open label treatment were evaluated for patients who received placebo versus OROS methylphenidate during the double-blind phase. In placebo-treated patients, mean (SD) blood pressure changed from $125.6(16.6)$ to 128.2 (16.6) $\mathrm{mmHg}$ for systolic and from 80.3 (11.0) to 84.2 (10.6) $\mathrm{mmHg}$ for diastolic from the end of double-blind treatment to the end of open-label. The corresponding changes were similar in OROS methylphenidate-treated patients; 124.4 (14.3) to 126.7 (15.5) $\mathrm{mmHg}$ and 80.5 (10.7) to 82.9 (10.6) $\mathrm{mmHg}$. Pulse increased from 80.2 (13.3) to 87.4 (14.3) bpm in placebo-treated and 84.6 (14.3) to 87.4 (13.7) bpm in OROS methylphenidate-treated patients.

Clinically relevant criteria for elevated/increased systolic ( $\geq 140 \mathrm{mmHg}$ ) or diastolic ( $\geq 90 \mathrm{mmHg}$ ) blood pressure, or pulse $(\geq 90 \mathrm{bpm})$ were predefined. The number $(\%)$ of patients who met these criteria at the last treatment visit (week 7) are presented by the patient's daily dose at this

Table 3 Percent of patients who reported an adverse event by daily dose and treatment period

\begin{tabular}{|c|c|c|c|c|c|}
\hline \multirow[t]{2}{*}{ Treatment period } & \multicolumn{5}{|c|}{ Daily dosage of OROS methylphenidate $(N=370)$} \\
\hline & $18 \mathrm{mg}$ & $36 \mathrm{mg}$ & $54 \mathrm{mg}$ & $72 \mathrm{mg}$ & $90 \mathrm{mg}$ \\
\hline Week I & $46 \%(46 / 10 I)$ & $44 \%(104 / 237)$ & $36 \%(4 / I I)$ & $0 \%(0 / I)$ & $100 \%(1 / 1)$ \\
\hline Week 3 & $38 \%(9 / 24)$ & $30 \%(40 / 133)$ & $49 \%(76 / 154)$ & $49 \%(16 / 33)$ & $0 \%(0 / 4)$ \\
\hline Week 7 & $33 \%(7 / 21)$ & $23 \%(19 / 82)$ & $26 \%(29 / 110)$ & $31 \%(20 / 65)$ & $38 \%(12 / 32)$ \\
\hline
\end{tabular}

Notes: Numerator is number of patients reporting any adverse event; denominator is total number of patients in the same dosage and treatment week. Excludes patients who took no drug on the visit day for the treatment week or did not attend the visit day (see Figure I).

Abbreviation: OROS, osmotic release oral system. 
Table 4 Adverse events by daily dose at final treatment visit

\begin{tabular}{|c|c|c|c|c|c|}
\hline \multirow[t]{2}{*}{ Adverse event, n (\%) } & \multicolumn{5}{|c|}{$\begin{array}{l}\text { Daily dosage of OROS methylphenidate } \\
(N=370)\end{array}$} \\
\hline & $18 \mathrm{mg}$ & $36 \mathrm{mg}$ & $54 \mathrm{mg}$ & $72 \mathrm{mg}$ & $90 \mathrm{mg}$ \\
\hline Headache & $2(9.5)$ & $2(2.4)$ & $4(3.6)$ & $5(7.7)$ & I (3.I) \\
\hline Decreased appetite & 0 & 0 & I (0.9) & $\mathrm{I}(\mathrm{I} .5)$ & $2(6.3)$ \\
\hline Insomnia & I (4.8) & $\mathrm{I}(\mathrm{I} .2)$ & $4(3.6)$ & $\mathrm{I}(\mathrm{I} .5)$ & I (3.I) \\
\hline Nausea & 0 & $\mathrm{I}(\mathrm{I} .2)$ & I $(0.9)$ & 0 & 0 \\
\hline Nasopharyngitis & $\mathrm{I}(4.8)$ & $6(7.3)$ & $3(2.7)$ & $3(4.6)$ & I (3.I) \\
\hline Restlessness & I (4.8) & $\mathrm{I}(1.2)$ & I $(0.9)$ & $2(3.1)$ & 0 \\
\hline Dry mouth & I (4.8) & 0 & 0 & 0 & I (3.I) \\
\hline Fatigue & 0 & $\mathrm{I}(1.2)$ & 0 & 0 & 0 \\
\hline Dizziness & I (4.8) & 0 & 0 & $\mathrm{I}(\mathrm{I} .5)$ & 0 \\
\hline Anxiety & I (4.8) & $2(2.4)$ & 0 & 0 & 0 \\
\hline Palpitations & I (4.8) & $\mathrm{I}(\mathrm{I} .2)$ & 0 & $\mathrm{I}(\mathrm{I} .5)$ & 0 \\
\hline Depressed mood & 0 & 0 & $2(1.8)$ & $2(3.1)$ & I (3.I) \\
\hline Tachycardia & 0 & $\mathrm{I}(\mathrm{I} .2)$ & I $(0.9)$ & $\mathrm{I}(\mathrm{I} .5)$ & 0 \\
\hline Nervousness & I (4.8) & 0 & 0 & 0 & 0 \\
\hline Influenza & 0 & 0 & 0 & $\mathrm{I}(\mathrm{I} .5)$ & 0 \\
\hline Disturbance in attention & 0 & 0 & 0 & $\mathrm{I}(\mathrm{I} .5)$ & I (3.I) \\
\hline
\end{tabular}

Notes: Adverse events reported in $>2 \%$ total patients (see Table 2 ); $\mathrm{n}=$ number of patients with a particular adverse event at week 7 visit; percentage denominator is total number of patients with the same dosage at final treatment week. Excludes patients who took no drug on the final visit day or did attend the visit (see Figure I). Abbreviation: OROS, osmotic release oral system.

visit in Table 5. For blood pressure and pulse, the percentage of patients who met these criteria appears similar across the lower three doses $(18,36,54 \mathrm{mg})$, with a trend for a larger percentage at the higher two doses (72 and $90 \mathrm{mg}$ ). The percentage of patients who met these criteria before entering the open-label phase varied across their double-blind treatment group: systolic (13\%-21\%), diastolic (14\%-25\%), and pulse $(22 \%-41 \%)$.

One patient discontinued trial medication due to raised blood pressure (systolic $125 \mathrm{mmHg}$ and diastolic $90 \mathrm{mmHg}$ ), which the investigator assessed as moderate in severity and probably drug-related. A second patient discontinued trial medication due to worsening of high blood pressure and paraesthesia. High blood pressure was reported at baseline of the double-blind phase (systolic $142 \mathrm{mmHg}$ and 94 diastolic $\mathrm{mmHg}$ ) and increased at the time of discontinuation of the open-label phase (systolic $184 \mathrm{mmHg}$ and diastolic $103 \mathrm{mmHg}$ ). The investigator assessed worsening of high blood pressure and paraesthesia feeling in right arm as moderate and mild in severity and very likely and possible related to study medication, respectively.

Tachycardia was reported as an adverse event in 10 patients (4\%) and 12 patients (3\%) experienced palpitations. One patient experienced tachycardia and discontinued trial medication ( $36 \mathrm{mg}$ daily) because of this adverse event. The investigator considered the adverse event as mild in severity and probably drug-related.

\section{Body weight}

Decreased weight was reported as an adverse event for seven subjects. One patient discontinued study medication because of decreased weight; a second patient discontinued trial medication because of decreased weight and decreased appetite; and a third patient reported decreased appetite as reason for discontinuing trial medication, along with other adverse events. There was a small mean (SD) decrease in weight of $-1.5 \mathrm{~kg}$ (2.29) over the seven-week treatment period.

\section{Efficacy assessment}

The primary efficacy measure during the open-label phase was the mean change in CAARS total score from the end of double-blind treatment, which was assessed using within-group two-sided paired $t$-tests. Patients who received placebo in the double-blind phase showed improvement with a significant mean decrease $(\mathrm{M}=-3.5, \mathrm{SD}=8.49)$ in CAARS total score after one week of treatment in the

Table 5 Patients who met clinically relevant criteria for cardiovascular-related measurements by daily dose at final treatment visit

\begin{tabular}{|c|c|c|c|c|c|}
\hline \multirow[t]{2}{*}{ Measurement, $\mathrm{n}(\%)$} & \multicolumn{5}{|c|}{ Daily dosage of OROS methylphenidate $(N=370)$} \\
\hline & $\begin{array}{l}\mid 8 \mathrm{mg} \\
\mathrm{n}=2 \text { | }\end{array}$ & $\begin{array}{l}36 \mathrm{mg} \\
\mathrm{n}=82\end{array}$ & $\begin{array}{l}54 \mathrm{mg} \\
\mathrm{n}=110\end{array}$ & $\begin{array}{l}72 \mathrm{mg} \\
\mathrm{n}=65\end{array}$ & $\begin{array}{l}90 \mathrm{mg} \\
\mathrm{n}=32\end{array}$ \\
\hline $\begin{array}{l}\text { Systolic blood pressure } \\
(\geq \mid 40 \mathrm{mmHg})\end{array}$ & $2(9.5)$ & $13(15.9)$ & $20(18.2)$ & $14(21.5)$ & II (34.4) \\
\hline $\begin{array}{l}\text { Diastolic blood pressure } \\
(\geq 90 \mathrm{mmHg})\end{array}$ & $6(28.6)$ & $23(28.0)$ & $25(22.7)$ & $22(33.8)$ & $12(37.5)$ \\
\hline $\begin{array}{l}\text { Pulse } \\
\text { ( } \geq 90 \text { beats per minute) }\end{array}$ & $7(33.3)$ & $29(35.4)$ & $37(33.6)$ & $32(49.2)$ & $16(50.0)$ \\
\hline
\end{tabular}

Note: Measured while patient standing; $\mathrm{n}=$ number of patients who met criteria; percentage denominator is total number of patients with the same dosage at final treatment week. Excludes patients who took no drug on the visit day for the treatment week or did not attend the visit day (see Figure I). 
open-label phase, and their total score further decreased at week $3(\mathrm{M}=-6.7, \mathrm{SD}=8.79)$ and week $7(\mathrm{M}=-8.5$, $\mathrm{SD}=9.65)(\mathrm{p}$ values $<0.001)$. Patients treated with OROS methylphenidate during double-blind phase showed a small improvement at week $1(\mathrm{M}=-0.6, \mathrm{SD}=7.96)$ and a larger significant decrease in their total score at week $3(\mathrm{M}=-4.3$, $\mathrm{SD}=8.21)$ and week $7(\mathrm{M}=-6.5,9.31)(\mathrm{p}$ values $<0.001$ at week 3 and 7).

\section{Discussion}

This seven-week open-label, flexible dosage extension of a five-week double-blind, fixed dose study provided further support for the safety and tolerability of OROS methylphenidate in a flexible dose regimen (18-90 mg daily) for the treatment of adults diagnosed with ADHD. The flexible dosing more closely parallels clinical practice than fixed dosing and consequently provides additional clinically relevant findings. Adverse events seldom lead to discontinuation of study medication and overall there was a very low discontinuation rate. The adverse events most frequently reported by patients included headache, decreased appetite, and insomnia. Adverse events were rarely serious. There were small increases in systolic and diastolic blood pressure and pulse.

The safety findings are comparable to other open-label studies of OROS methylphenidate in the treatment of ADHD in adults, although previous studies treated a smaller number of patients. Biederman and colleagues reported a six-week study in 36 adults with late-onset ADHD, Fallu and colleagues treated 30 adults with ADHD for 38 days, and Ramos-Quiroga and colleagues treated 70 adults with ADHD for 90 days, and all studies observed that the medication was well tolerated. ${ }^{28-30}$ With a much larger sample of 370 patients, the open-label findings reported herein significantly enhances our confidence that prolonged-release OROS methylphenidate is a well tolerated therapy for the treatment of adults with ADHD.

The seven-week open-label safety findings were generally consistent with the five-week fixed-dose double-blind phase of the trial. ${ }^{23}$ The small increases in systolic and diastolic blood pressure and pulse during the open-label phase were comparable to the double-blind phase. Medications used to treat ADHD including methylphenidate compounds are associated with small increases on heart rate and blood pressure, but the changes are usually modest with no clinically significant changes. ${ }^{13,14}$ As discussed in guidelines for the use of these medications for the treatment of ADHD in children and adults, the potential cardiovascular effects are generally considered acceptable and manageable and can be monitored as the physician feels necessary. ${ }^{9,31}$ As well, all drug products for the treatment of ADHD provide patient medication guides to inform about possible cardiovascular effects associated with of the medication. ${ }^{15}$

As discussed by Godfrey and Rostain, when choosing a medication for treating adults with ADHD, important considerations are the control of symptoms throughout the working day with a regimen that may enhance adherence, and a formulation that can minimize the possible misuse of the medication. ${ }^{13,14}$ The osmotic controlled-release technology of the once-daily OROS methylphenidate formulation achieves a rapid onset of effect and delivers methylphenidate in a controlled manner for approximately 12 hours, thereby allowing extended coverage of symptoms during the day. ${ }^{19,32}$ In addition, the physical properties of the OROS mechanism of delivery reduce the risk of possible methylphenidate substance abuse. ${ }^{33}$

In this open-label study, investigators adjusted the dose to optimize efficacy and tolerability for each patient based on their judgment of clinical response. The majority of patients $(85 \%)$ received $36 \mathrm{mg}, 54 \mathrm{mg}$, or $72 \mathrm{mg}$ as their last daily dose; the $54 \mathrm{mg}$ dose was most frequently administered as a last dose and maximum dose. For the three most frequently administered dosages, the incidence of adverse events decreased over time, suggesting that investigators were adjusting the dosage to optimize tolerability. However, this decrease may reflect, at least partially, longer exposure to the medication and increased tolerance in the patients. Along with the decrease in adverse events, patients continued to show improvements on the measure of efficacy (ie, decreases in CAARS total score) during the open-label phase. This result, along with the safety findings, suggests that investigators were able to optimize the daily dosage for a patient to achieve a balance between maintaining efficacy and minimizing adverse events.

There are a number of limitations associated with the reported study. The results covered a seven-week treatment period and did not provide information on the long-term safety of OROS methylphenidate treatment of ADHD in adults. Patients were not randomized which may limit the overall conclusions. Sample size was relatively large compared to other studies but not of the magnitude required to evaluate the possibility of rare adverse events. Patients with other Axis I disorder or patients with a high cardiovascular risk profile were excluded and there was limited ethnical/racial diversity. Concomitant psychotherapy 
or other therapeutic options were not administered to improve the treatment effect.

In conclusion, the seven-week open-label results provided additional support for the safety and tolerability of prolonged-release OROS methylphenidate in a flexible dose regimen for the treatment of adults diagnosed with ADHD. Moreover, the findings provided further guidance for usual medical care for the treatment of ADHD in adults in that most patients have the optimal trade-off between efficacy and absence of side effects with dosages of 36, 54, or $72 \mathrm{mg}$ /day.

\section{Acknowledgments}

This study was supported by Janssen Pharmaceutica NV, Belgium. Susan Glasser, PhD, of Johnson and Johnson Pharmaceutical Research and Development, LLC, provided editorial review. The following investigators enrolled patients in the study: Czech Republic: Ceskova, Eva, MD; Raboch, Jiri, MD; Denmark: Arngrim, Torben, MD; Brødsgaard, Mogens Anders, MD; Erenbjerg, Ane-Marie, MD; Nicholson, Klavs, MD; Wernlund, Hans Henrik, MD; Finland: Henttonen, Antti Juhani, MD; Korkeila, Jyrki, MD; Niemelä, Asko Aukusti, MD; Sorvaniemi, Marko Petri, MD; France: Bouvard, Manuel, MD, PhD; Konofal, Eric, MD; Germany: Colla, Michael, MD; Gastpar, Markus, MD; Heinz, Andreas, MD; Imhof, Lothar, MD; Klein, Martin, MD; Krause, Johanna, MD; Lee, Sun-Hee, MD; Niemczyk, Wolfgang, MD; Nissen, Thomas, MD; Philipsen, Alexandra, MD; Rösler, Michael, MD; Sobanski, Esther, MD; Trott, Götz-Erik, MD; Greece: Christianopoulos, Kriton, MD; Koumoula, Anastasia, MD; Soldatos, Constantin, PhD, MD; Netherlands: Buitelaar, Jan, MD, PhD; Kooij, Sandra, MD, PhD; Norway: Auglænd, Odd, MD; Hustoft, Hilde, MD; Nyrerød, Hans Jørgen, MD; Portugal: Ferreira, Luis, MD; Filipe, Carlos, MD ; Spain: Casas, Miguel, MD, PhD; Sweden: Ginsberg, Ylva, MD; Guldberg-Kjär, Niels, MD; Lindström, Eva, Assistant PhD MD; Maahr, Eija, MD; Woxler, Per, MD; Switzerland: Eich, Dominique, MD, MD; Grossenbacher, Jürg, MD; Hofecker Fallahpour, Maria, MD; United Kingdom: Adamou, Marios, MD; Kumar, Vinod, MD; Rogers, Danny, MD.

\section{Disclosures}

Bradford Challis, $\mathrm{PhD}$, is a full-time employee of Johnson \& Johnson Pharmaceutical Research and Development, LLC, and Dr Medori was a full-time employee of Janssen-Cilag. Joachim Dejonckheere, $\mathrm{PhD}$, is a consultant of SGS Life Sciences and provided statistical services under a contract with
Janssen-Cilag. Drs Buitelaar, Casas, Kooij, and Ramos-Quiroga have served as consultants for Janssen-Cilag.

\section{References}

1. Feifel D. Commentary: why diagnose and treat ADHD in adults? Postgrad Med. 2008;120(3):13-15.

2. Asherson P. Clinical assessment and treatment of attention deficit hyperactivity disorder in adults. Expert Rev Neurother. 2005;5(4): 525-539.

3. Asherson P, Chen W, Craddock B, Taylor E. Adult attention-deficit hyperactivity disorder: recognition and treatment in general adult psychiatry. Br J Psychiatry. 2007;190:4-5.

4. Faraone SV, Biederman J, Mick E. The age-dependent decline of attention deficit hyperactivity disorder: a meta-analysis of follow-up studies. Psychol Med. 2005;35:1-7.

5. Fayyad J, De Graaf R, Kessler R, et al. Cross-national prevalence and correlates of adult attention-deficit hyperactivity disorder. $\mathrm{Br} \mathrm{J}$ Psychiatry. 2007;190:402-409.

6. Kessler RC, Adler L, Barkley R, et al. The prevalence and correlates of adult ADHD in the United States: results from the National Comorbidity Survey Replication. Am J Psychiatry. 2006;163(4):716-723.

7. Kessler RC, Adler LA, Barkley R, et al. Patterns and predictors of attention-deficit/hyperactivity disorder persistence into adulthood: results from the national comorbidity survey replication. Biol Psychiatry. 2005;57(11):1442-1451.

8. Greenhill LL, Pliszka S, Dulcan MK, et al. Summary of the practice parameter for the use of stimulant medications in the treatment of children, adolescents, and adults. J Am Acad Child Adolesc Psychiatry. 2001;40(11):1352-1355.

9. Nutt DJ, Fone K, Asherson P, et al. Evidence-based guidelines for management of attention-deficit/hyperactivity disorder in adolescents in transition to adult services and in adults: recommendations from the British Association for Psychopharmacology. J Psychopharmacol. 2007;21(1):10-41.

10. Kooij JJ, Buitelaar JK, van den Oord EJ, Furer JW, Rijnders CA, Hodiamont PP. Internal and external validity of attention-deficit hyperactivity disorder in a population-based sample of adults. Psychol Med. 2005;35(6):817-827.

11. Kooij JJ, Burger H, Boonstra AM, Van der Linden PD, Kalma LE, Buitelaar JK. Efficacy and safety of methylphenidate in 45 adults with attention-deficit/hyperactivity disorder. A randomized placebocontrolled double-blind cross-over trial. Psychol Med. 2004; 34(6):973-982.

12. Banaschewski T, Coghill D, Santosh P, et al. Long-acting medications for the hyperkinetic disorders. A systematic review and European treatment guideline. Eur Child Adolesc Psychiatry. 2006;15(8):476-495.

13. Godfrey J. Safety of therapeutic methylphenidate in adults: a systematic review of the evidence. $J$ Psychopharmacol. 2009;23(2): 194-205.

14. Rostain AL. Attention-deficit/hyperactivity disorder in adults: evidence-based recommendations for management. Postgrad Med. 2008;120(3):27-38.

15. US Food and Drug Administration. FDA Directs ADHD Drug Manufacturers to Notify Patients about Cardiovascular Adverse Events and Psychiatric Adverse Events. Rockville, MD: National Press Office; February 21, 2007. Press pp. 07-26.

16. Nissen SE. ADHD drugs and cardiovascular risk. $N$ Engl $J$ Med. 2006;354(14):1445-1448.

17. Okie S. ADHD in adults. N Engl J Med. 2006;354(25):2637-2641.

18. Pelham WE, Gnagy EM, Burrows-Maclean L, et al. Once-a-day Concerta methylphenidate versus three-times-daily methylphenidate in laboratory and natural settings. Pediatrics. 2001;107(6):E105.

19. Swanson J, Gupta S, Lam A, et al. Development of a new once-a-day formulation of methylphenidate for the treatment of attention-deficit/ hyperactivity disorder: proof-of-concept and proof-of-product studies. Arch Gen Psychiatry. 2003;60(2):204-211. 
20. Wolraich ML, Greenhill LL, Pelham W, et al. Randomized, controlled trial of oros methylphenidate once a day in children with attention-deficit/hyperactivity disorder. Pediatrics. 2001;108(4): 883-892.

21. Adler LA, Zimmerman B, Starr HL, et al. Efficacy and safety of OROS methylphenidate in adults with attention-deficit/hyperactivity disorder: a randomized, placebo-controlled, double-blind, parallel group, dose-escalation study. J Clin Psychopharmacol. 2009; 29(3):239-247.

22. Biederman J, Mick E, Surman C, et al. A randomized, placebocontrolled trial of OROS methylphenidate in adults with attentiondeficit/hyperactivity disorder. Biol Psychiatry. 2006;59(9):829-835.

23. Medori R, Ramos-Quiroga JA, Casas M, et al. A randomized, placebo-controlled trial of three fixed dosages of prolonged-release OROS methylphenidate in adults with attention-deficit/hyperactivity disorder. Biol Psychiatry. 2008;63(10):981-989.

24. Reimherr FW, Williams ED, Strong RE, Mestas R, Soni P, Marchant BK. A double-blind, placebo-controlled, crossover study of osmotic release oral system methylphenidate in adults with ADHD with assessment of oppositional and emotional dimensions of the disorder. J Clin Psychiatry. 2007;68(1):93-101.

25. American Psychiatric Association. Diagnostic and Statistical Manual of Mental Disorders, Fourth Edition, Text Revision. Washington, DC: The American Psychiatric Association; 2000.

26. Conners C, Erhardt D, Sparrow E. Conners'Adult ADHD Rating Scales (CAARS): Technical Manual. North Tonawanda, NY: Multi-Health Systems; 1999.
27. First M, Spitzer R, Gibbon M, Williams G. Structured Clinical Interview for DSM-IV Axis I Disorders, Patient Edition (SCID-P), Version 2. New York, NY: New York State Psychiatric Institute, Biometrics Research; 1994.

28. Biederman J, Mick E, Spencer T, et al. An open-label trial of OROS methylphenidate in adults with late-onset ADHD. CNS Spectr. 2006;11(5):390-396.

29. Fallu A, Richard C, Prinzo R, Binder C. Does OROS-methylphenidate improve core symptoms and deficits in executive function? Results of an open-label trial in adults with attention deficit hyperactivity disorder. Curr Med Res Opin. 2006;22(12):2557-2566.

30. Ramos-Quiroga JA, Bosch R, Castells X, et al. Effect of switching drug formulations from immediate-release to extended-release OROS methylphenidate : a chart review of Spanish adults with attention-deficit hyperactivity disorder. CNS Drugs. 2008;22(7):603-611.

31. Vetter VL, Elia J, Erickson C, et al. Cardiovascular monitoring of children and adolescents with heart disease receiving stimulant drugs: a scientific statement from the American Heart Association Council on Cardiovascular Disease in the Young Congenital Cardiac Defects Committee and the Council on Cardiovascular Nursing. Circulation. 2008;117(18):2407-2423.

32. Modi NB, Lindemulder B, Gupta SK. Single- and multiple-dose pharmacokinetics of an oral once-a-day osmotic controlled-release OROS (methylphenidate $\mathrm{HCl}$ ) formulation. J Clin Pharmacol. 2000;40(4):379-388.

33. Bukstein O. Substance abuse in patients with attention-deficit/ hyperactivity disorder. Medscape J Med. 2008;10(1):24.
Neuropsychiatric Disease and Treatment

\section{Publish your work in this journal}

Neuropsychiatric Disease and Treatment is an international, peerreviewed journal of clinical therapeutics and pharmacology focusing on concise rapid reporting of clinical or pre-clinical studies on a range of neuropsychiatric and neurological disorders. This journal is indexed on PubMed Central, the 'PsycINFO' database and CAS, and is the official

\section{Dovepress}

journal of The International Neuropsychiatric Association (INA). The manuscript management system is completely online and includes a very quick and fair peer-review system, which is all easy to use. Visit http://www.dovepress.com/testimonials.php to read real quotes from published authors. 